\title{
Lightweight Hierarchical Carbon Nanocomposites with Highly Efficient and Tunable Electromagnetic Interference Shielding Properties
}

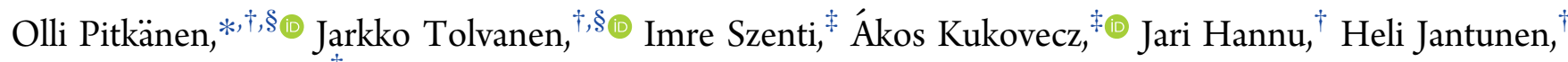 \\ and Krisztian Kordas ${ }^{\dagger}$ \\ ${ }^{\dagger}$ Microelectronics Research Unit, Faculty of Information Technology and Electrical Engineering, University of Oulu, P.O. Box 4500, \\ FIN-90014 Oulu, Finland \\ ${ }^{\ddagger}$ Interdisciplinary Excellence Centre, Department of Applied and Environmental Chemistry, University of Szeged, H-6720 Szeged, \\ Rerrich Béla tér 1, Hungary
}

\section{Supporting Information}

ABSTRACT: High-performance electromagnetic interference shielding is becoming vital for the next generation of telecommunication and sensor devices among which portable and wearable applications require highly flexible and lightweight materials having efficient absorption-dominant shielding. Herein, we report on lightweight carbon foam-carbon nanotube/carbon nanofiber nanocomposites that are synthesized in a two-step robust process including a simple carbonization of open-pore structure melamine foams and subsequent growth of carbon nanotubes/nanofibers by chemical vapor deposition. The microstructure of the nanocomposites resembles a 3-dimensional hierarchical net-

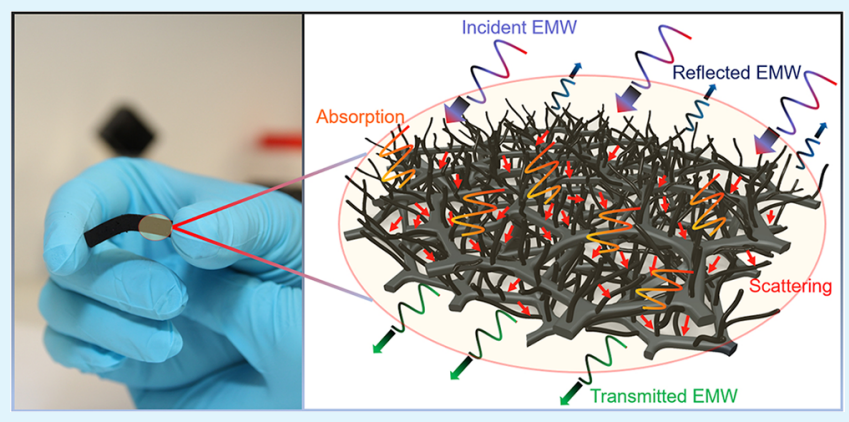
work of carbonaceous skeleton surrounded with a tangled web of bamboo-shaped carbon nanotubes and layered graphitic carbon nanofibers. The microstructure of the porous composite enables absorption-dominant (absorbance $\sim 0.9$ ) electromagnetic interference shielding with an effectiveness of $\sim 20-30 \mathrm{~dB}$ and with an equivalent mass density normalized shielding effectiveness of $\sim 800-1700 \mathrm{~dB} \mathrm{~cm}^{3} \mathrm{~g}^{-1}$ at the K-band frequency $(18-26.5 \mathrm{GHz})$. Moreover, the hydrophobic nature of the materials grants water-repellency and stability in humid conditions important for reliable operation in outdoor use, whereas the mechanical flexibility and durability with excellent piezoresistive behavior enable strain-responsive tuning of electrical conductivity and electromagnetic interference shielding, adding on further functionalities. The demonstrated nanocomposites are versatile and will contribute to the development of reliable devices not only in telecommunication but also in wearable electronics, aerospace engineering, and robotics among others.

KEYWORDS: carbon foam, carbon nanotubes, flexible, melamine foam, nanocomposite, piezoresistive, lightweight, electromagnetic interference shielding

\section{INTRODUCTION}

High-performance electromagnetic interference (EMI) shielding based on advanced functional materials are of high demand for the next-generation portable and wearable devices, as they play a key role in reducing the adverse effects of electromagnetic radiation on electrical components thus enabling future reliable technologies related to the internet-of-things and digitalization. These materials are anticipated to be lightweight and flexible yet durable and stable in harsh environments. In particular, quickly developing wireless and telecommunications technologies create even further stringent demands on such materials (wideband performance, tunability, frequency selectivity, etc.).

Attenuation of electromagnetic waves in homogeneous media is largely dependent on the interaction of the radiation with dipoles, free carriers, defects, and impurities, which induce respective polarization and ohmic losses, scattering, and, ultimately, absorption. On the other hand, in multiphase materials, additional scattering of the waves occurs at the interfaces of different phases. The degree of such interfacial scattering is a function of the impedance mismatch between the corresponding media that depends on the dielectric permittivity and magnetic permeability of the phases. In such systems, therefore, shielding is a consequence of multiple scattering events in the medium, which inherently increase the path of propagation and consequently the attenuation of electromagnetic waves.

Received: February 4, 2019

Accepted: May 6, 2019

Published: May 6, 2019 


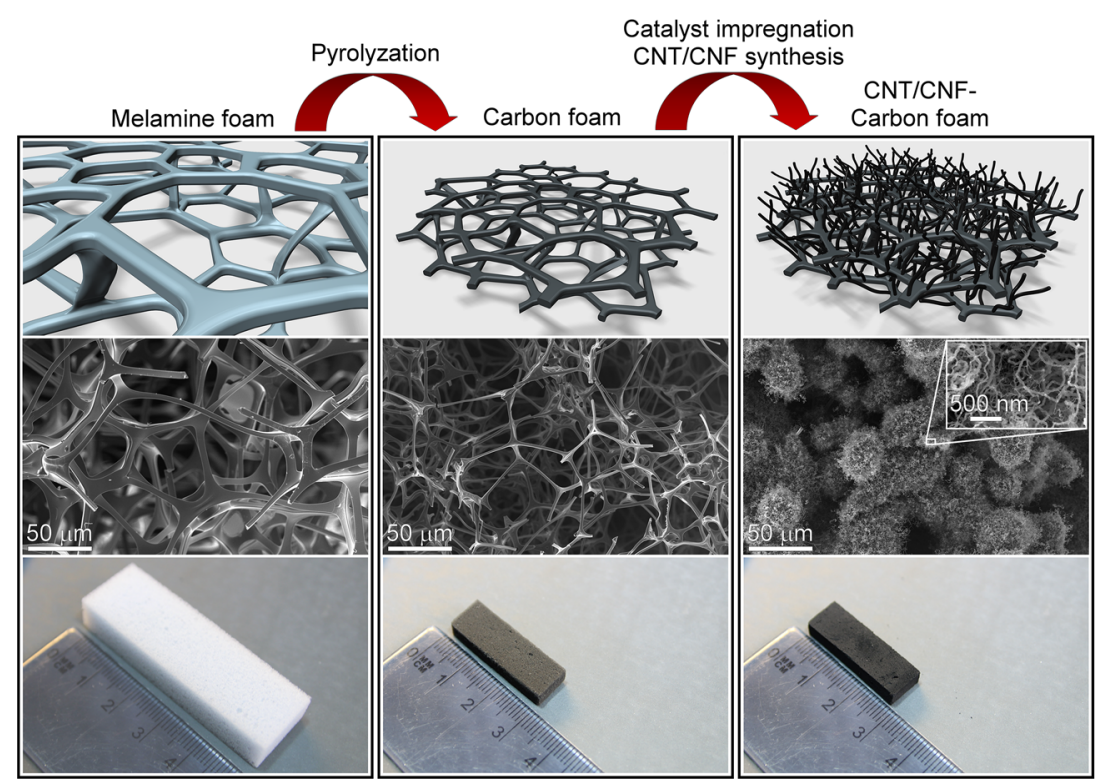

Figure 1. Illustration of the preparation process of lightweight carbon-based nanocomposites. Schematic drawing, FESEM images, and digital camera images of melamine foam, carbon foam, and hierarchical nanocomposite (CNTs/CNFs@C foam, density of $30 \mathrm{mg} / \mathrm{cm}^{3}$ ).

Because of their absorption-dominant shielding, lightweight, corrosion resistance, flexibility, and facile large-scale production, ${ }^{1-5}$ conducting polymer composites have been adapted instead of conventional reflection-loss based metal shielding materials. To achieve good electrical conductivity of composites, necessary for high-performance EMI shielding applications, percolated networks of high aspect ratio metal nanowires (typically Ag), ${ }^{6-10}$ carbon nanotubes (CNTs), ${ }^{1-3,11,12}$ or large flakes of 2-dimensional materials such as graphene, ${ }^{4,13-19}$ reduced graphene oxide $(\mathrm{rGO}){ }^{5,16,20-22}$ as well as MXenes, ${ }^{23-26}$ are utilized as fillers. Recently, also biobased materials such as carbonized cellulose, ${ }^{8,11}$ cork, $^{7}$ and wood pulp $^{27}$ derived carbon nanostructures have been reported.

The ultimate absorption-dominant shielding material requires not only high electrical conductivity but also lightweight and/or thin structures that can be applied as an envelope around the volume to be protected (or at a welldefined surface area behind which the radiation shall be reduced/eliminated). In addition, for high-power applications, good thermal conductivity may be a further demand, as the generated heat of the absorbed and transformed electromagnetic energy has to be sufficiently dissipated to avoid excessive heating of devices. Introduction of pores and thus forming cell-like microstructures has been found to be effective in producing conductive networks at lower fillers loadings, ${ }^{17}$ reduced weight, ${ }^{2}$ and low impedance mismatch between the two media. ${ }^{1,16}$ This latter is particularly important for absorption-dominant shielding, since it facilitates multiple scattering of electromagnetic waves in the material leading to an efficient wave power attenuation in the conductive phase. ${ }^{6,17}$

Various three-dimensional (3D) conductive networks of porous conductive materials $3,4,6,11-14,16,20,22,23,28,29$ can be directly made for instance by self-assembly, chemical vapor deposition, freeze-drying, ${ }^{12,17}$ and chemical leaching.,11-13,17 However, owing to their low costs and multifunctional properties, ${ }^{30}$ carbon foams derived from open-pore structure melamine foams by simple carbonization (pyrolysis) have attracted immense interest and have been demonstrated as absorbers of nonpolar solvents, ${ }^{30,31}$ catalyst support, ${ }^{32-34}$ piezoresistive sensors, ${ }^{35,36}$ supercapacitor electrodes, ${ }^{37}$ and collectors for battery electrodes. ${ }^{38-40}$ Very recently, composites of carbonized melamine foams with metal nanoparticles, graphene, and polydimethylsiloxane (PDMS) were found useful also in EMI shielding, ${ }^{41}$ although with a moderate specific shielding effectiveness caused by the high mass density of the applied polymer matrices.

Furthermore, flexible/stretchable conductive materials often display large piezoresistive strain gauge factors, i.e., change their resistivity under mechanical deformation. Such a property may be exploited in strain-responsive tuning of EMI shielding, ${ }^{13,42}$ which is not possible with conventional materials. On the one hand, when applying strain, percolation in the conductive network change resulting in an increased/ decreased conductivity under compressive/tensile stress. On the other hand, in the case of nonmetallic conductors (semiconductors and disordered carbon nanomaterials), the electronic band structure can also change thus giving rise to further variation of the electrical properties (i.e., conductivity and dielectric permittivity) thus contributing to a modified EMI shielding behavior.

Herein, we combine all strategies to propose a new generation of EMI shielding materials that are lightweight, water repellent, flexible, and stable in humid conditions and have excellent absorption-dominant as well as mechanically tunable shielding properties. We apply carbon based porous hierarchical nanocomposites synthesized using robust easy-toscale methods. First, porous carbon foam scaffolds are made by the pyrolysis of open-cell structure melamine foams, and then carbon nanotubes/nanofibers are grown on the structures using chemical vapor deposition. The novel nanocomposites are capable of providing highly efficient absorption-dominant ( $\sim 90 \%)$ and tunable EMI shielding (20-30 dB at a composite thickness of $5 \mathrm{~mm}$ ) at the K-band frequencies $(18-26.5 \mathrm{GHz}$, important for 5G telecommunication networks) $)^{43}$ with a corresponding specific shielding effectiveness up to $\sim 1700 \mathrm{~dB}$ $\mathrm{cm}^{3} \mathrm{~g}^{-1}$, which is among the highest of reported values. 
Accordingly, the above-mentioned properties of the demonstrated nanocomposites are not only fascinating but very practical making them promising candidates for future EMI shielding applications in for instance $5 \mathrm{G}$ telecommunication systems, portable and wearable electronics, aerospace and robotics engineering, sensors, and even in military defense.

\section{RESULTS AND DISCUSSION}

The synthesis of the nanocomposites is illustrated in Figure 1. A commercial open pore melamine $\left(n \cdot \mathrm{C}_{3} \mathrm{H}_{6} \mathrm{~N}_{6}\right)$ foam with density of $\sim 10 \mathrm{mg} / \mathrm{cm}^{3}$ was first carbonized at $800{ }^{\circ} \mathrm{C}$ to form carbon foam. During the process, the polymer foam shrank to $\sim 10 \%$ of its original volume while retaining the same foam structure and density. In the next step, the precursor of catalyst (nickel acetylacetonate, $\mathrm{Ni}(\mathrm{acac})_{2}$ ) dissolved in acetone for CNT growth was impregnated in the foam and then decomposed and reduced in $\mathrm{H}_{2}$ flow to form catalytically active metallic nickel nanoparticles. Finally, carbon nanotubes and nanofibers were synthesized by water assisted chemical vapor deposition (WA-CVD) at $770{ }^{\circ} \mathrm{C}$ in the same tube furnace by switching the gas flow for acetylene as carbon source filling the carbon foam skeletal structure with CNTs and CNFs (Figures S1 and S2, Supporting Information).

The achieved foam structures were found to be lightweight (Figure $2 \mathrm{a}$ ) with a mass density of $14-35 \mathrm{mg} / \mathrm{cm}^{3}$ depending
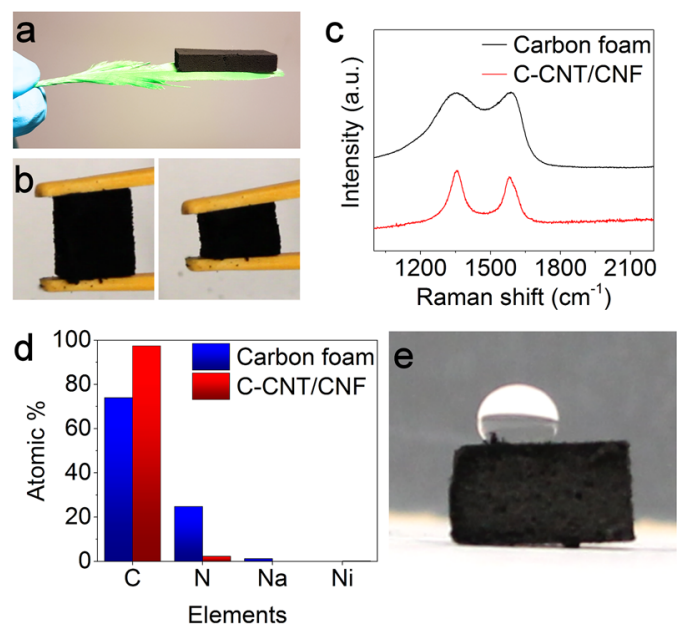

Figure 2. (a) Digital camera image of $\mathrm{C}-\mathrm{CNT} / \mathrm{CNF}$ foam composite $(\sim 50 \mathrm{mg})$ placed on an artificial feather and (b) compressed with tweezers. (c) Raman spectra of carbon foam and C-CNT/CNF foam composite $\left(30 \mathrm{mg} / \mathrm{cm}^{3}\right)$. (d) EDX element data from carbon foam and $\mathrm{C}-\mathrm{CNT} / \mathrm{CNF}$ foam composite $\left(30 \mathrm{mg} / \mathrm{cm}^{3}\right)$. (e) Water droplet on the hydrophobic surface of $\mathrm{C}-\mathrm{CNT} / \mathrm{CNF}$ foam composite (30 $\left.\mathrm{mg} / \mathrm{cm}^{3}\right)$.

on the amount of CNTs/CNFs in the parent carbon foam. The hierarchical carbon nanocomposites retained the excellent flexibility of the original carbon foam. (Figure 2b; Movie S1, Supporting Information). The variance of the amount of catalyst precursor may be used to adjust the mass of the grown CNTs/CNFs thus producing composites with different mass densities. The CNTs and CNFs grew in bundles on the carbon foam skeleton (Figure S2, Supporting Information) and significantly increase the specific surface area of the material (Table S1, Supporting Information). As expected, each carbon based foam is thermally insulating $(<0.1 \mathrm{~W} / \mathrm{m} \mathrm{K})$ due to the very low fraction of solid content in the material, which may be considered as a 3D network of micro and nanowires. The thermal conductivity of the composites is even slightly worse than that of the original carbon foam despite the added CNTs and CNFs, which may be considered as very poorly connected networks for the phonon transport. (Table S2, Supporting Information). The Raman spectrum of a typical carbon foam shows poor ordering of the $\mathrm{sp}^{2}$ and $\mathrm{sp}^{3}$ hybridized carbons suggesting that the material consists mostly of amorphous carbon, whereas the nanotubes and the nanofibers in the composite appears to be crystalline with large amount of defects (Figure 2c). Elemental analysis by energy-dispersive $\mathrm{X}$ ray spectroscopy (EDX) (Figure $2 \mathrm{~d}$ ) indicates high concentration of nitrogen within the carbon foam structure with small amount of sodium as previously reported. ${ }^{31}$ The carbon content significantly increases upon $\mathrm{CNT} / \mathrm{CNF}$ growth, while only traces of $\mathrm{Ni}$ catalyst $(<0.2$ at. \%) are found in the composite. Transmission electron micrographs (Figure S3, Supporting Information) indicate that the CNTs are bambooshaped and have diameters varying from 10 to $50 \mathrm{~nm}$. The reason for the formation of bamboo structures is likely the poor stability of the catalyst on the carbonaceous surface of the skeleton. The carbon nanofiber structures on the other hand consist of stacked graphitic layers and have diameters between 40 and $200 \mathrm{~nm}$. The formation of such nanofibers is due to the presence of large catalyst particles that are not suitable for growing tubular structures, only stacks of graphitic layers. In addition, no catalyst is found in the tips of the CNTs indicating base growth mechanism, which means that the catalyst remains in contact with the carbon substrate throughout the growth process.

The carbon and composite foams show very different wetting behavior. The carbon foam carbonized at $800{ }^{\circ} \mathrm{C}$ was found to be easily wetted and softened in water as previously reported. ${ }^{31,32}$ In contrast, because of the intrinsically hydrophobic nature of pristine carbon nanotubes and nanofibers as well as their the much larger surface area (Table S1, Supporting Information), the composite is highly hydrophobic. The measured contact angle of $125^{\circ}$ suggests superior waterrepellency and thus durability and stability in wet conditions and environments (Figure 2e, Movie S2, Supporting Information). This is in excellent agreement with our experiments that show insignificant variation of the electrical resistivity upon changing relative humidity between $20 \%$ and $80 \%$ at $21{ }^{\circ} \mathrm{C}$ (Figure S4, Supporting Information).

The mechanical characteristics under compressive strain $\left(\varepsilon_{\mathrm{c}}\right)$ show high flexibility and compressibility up to $\sim 40 \%$ (Figure 3) that was found to be reversible after the first compression cycle. Both types of foams undergo a minor but permanent collapse of the cell-structure on the first compression cycle alternating subsequent strain responses. Therefore, the deformation of the nanocomposites are entirely dominated by the bending of the cell walls (open-cell structure) at the reversible stress-strain region (i.e., linear elasticity; Figure 3ac) ${ }^{44}$ The Young's moduli for carbon and composite foams after the first compression cycle were found to be very low in the strain region of $10-30 \%$ (4-14 $\mathrm{kPa}$ for carbon foam, $10-$ $12 \mathrm{kPa}$ for $14 \mathrm{mg} / \mathrm{cm}^{3} \mathrm{C}-\mathrm{CNT} / \mathrm{CNF}$, and $8-21 \mathrm{kPa}$ for 35 $\left.\mathrm{mg} / \mathrm{cm}^{3} \mathrm{C}-\mathrm{CNT} / \mathrm{CNF}\right)$. Such an easily compressible soft open pore microstructure allows conformal fit and integration, e.g., in wearable devices. Also, the foams show considerable piezoresistive behavior as shown by the nearly 3 orders of magnitude drop of resistance measured at a compressive strain of $40 \%$ corresponding to an increased conductivity up to 0.007 


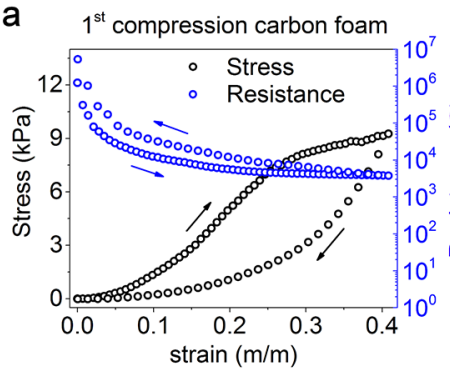

d $1^{\text {st }}$ compression $14 \mathrm{mg} / \mathrm{cm}^{3}$ composite

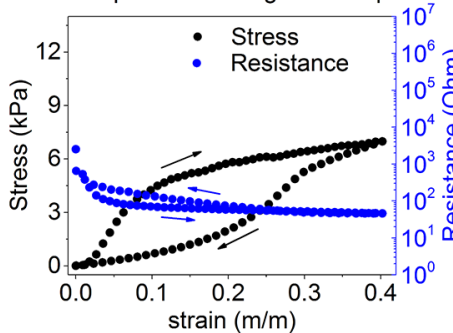

$\mathrm{g}_{1^{\text {st }} \text { compression } 35 \mathrm{mg} / \mathrm{cm}^{3} \text { composite }}$

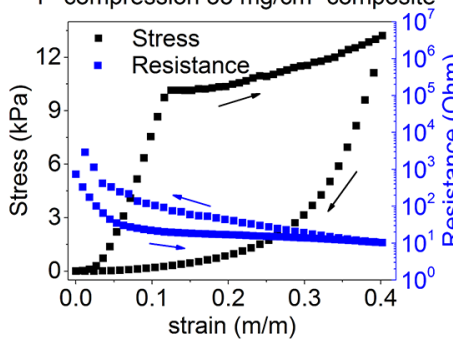

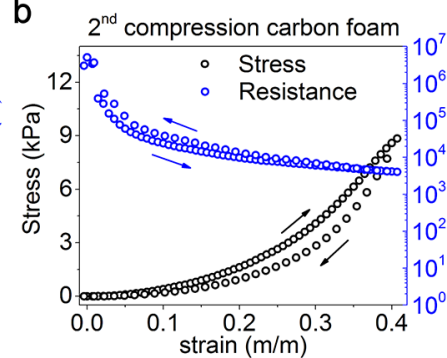

e $2^{\text {nd }}$ compression $14 \mathrm{mg} / \mathrm{cm}^{3}$ composite

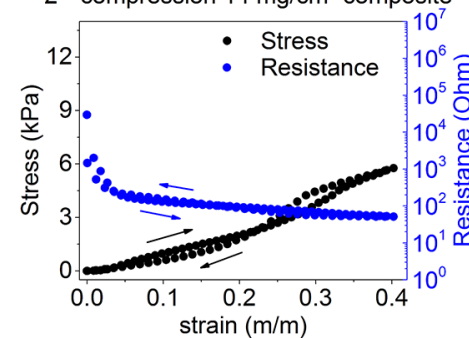

h $2^{\text {nd }}$ compression $35 \mathrm{mg} / \mathrm{cm}^{3}$ composite

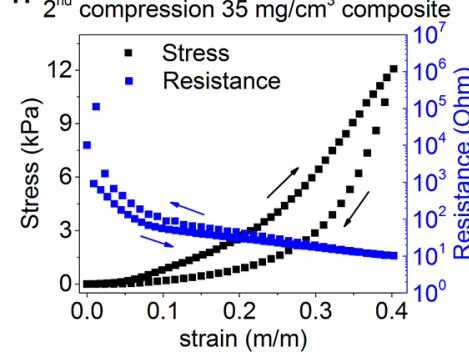

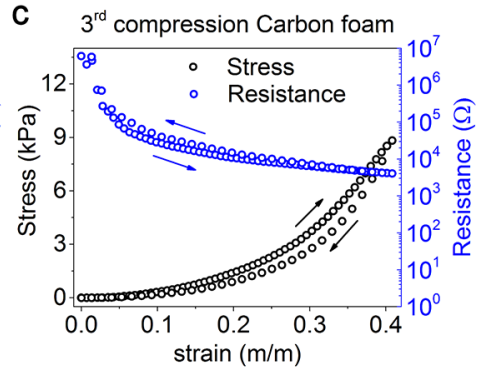

f $3^{\text {rd }}$ compression $14 \mathrm{mg} / \mathrm{cm}^{3}$ composite

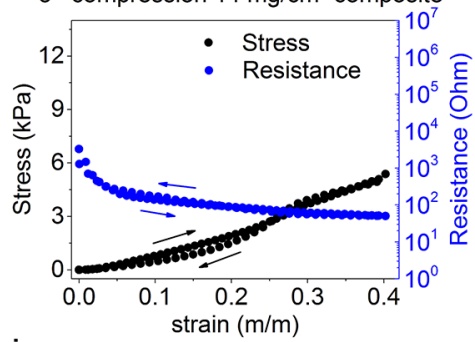

i $3^{\text {rd }}$ compression $35 \mathrm{mg} / \mathrm{cm}^{3}$ composite

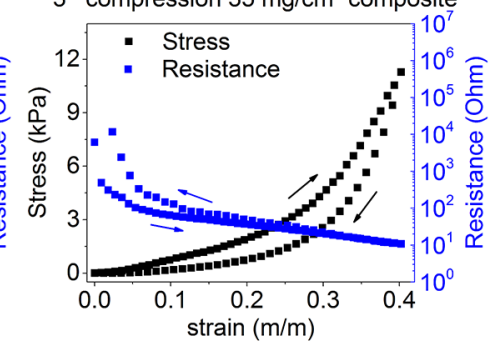

Figure 3. Stress-strain and piezoresistive behavior of the carbon foam in the (a) first, (b) second, and (c) third compression cycle. Panels $d-f$ display the same for the $14 \mathrm{mg} / \mathrm{cm}^{3}$ and panels $\mathrm{g}-\mathrm{i}$ show thoses for the $35 \mathrm{mg} / \mathrm{cm}^{3}$ nanocomposite, respectively.
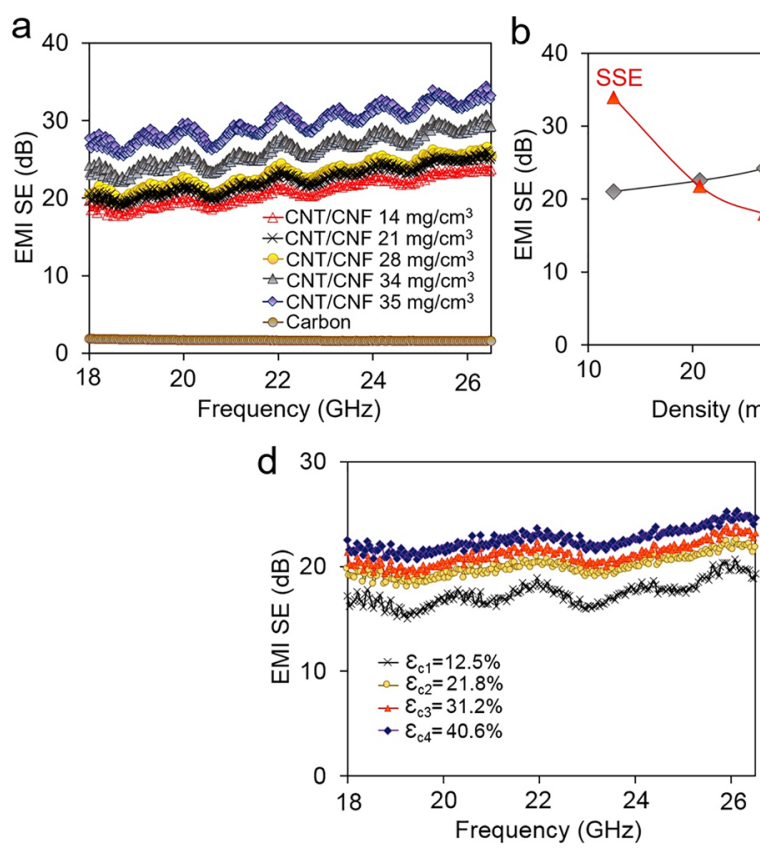
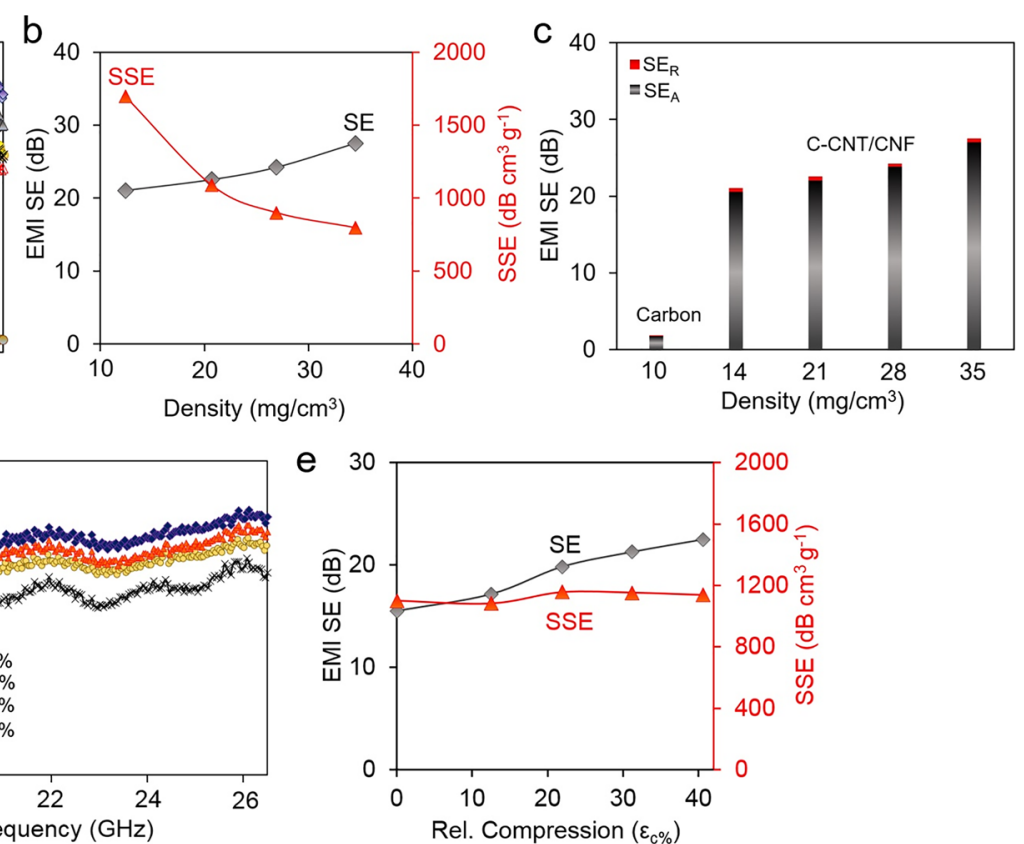

Figure 4. (a) Electromagnetic shielding effectiveness (SE) for carbon and composite foams with densities of $10-35 \mathrm{mg} / \mathrm{cm}^{3}$ at K-band frequencies, (b) SE and specific SE (SSE) as a function of density, and (c) the contribution of reflection $\left(\mathrm{SE}_{\mathrm{R}}\right)$, absorption ( $\left.\mathrm{SE}_{\mathrm{A}}\right)$ losses to the total shielding $\left(\mathrm{SE}_{\mathrm{T}}\right)$ for the carbon foam (density of $10 \mathrm{mg} / \mathrm{cm}^{3}$ ) and hierarchical composite structures (densities of $14,21,28$, and $\left.35 \mathrm{mg} / \mathrm{cm}^{3}\right)$. $(\mathrm{d}) \mathrm{SE}$ for the composite of $14 \mathrm{mg} / \mathrm{cm}^{3}$ density at compressive strains between $12.5 \%$ and $40.6 \%$ measured for the K-band frequencies (e) SE and SSE as a function of compressive strain (at $18 \mathrm{GHz})$.

$\mathrm{S} / \mathrm{m}$ (carbon foam), $0.9 \mathrm{~S} / \mathrm{m}\left(14 \mathrm{mg} / \mathrm{cm}^{3} \mathrm{C}-\mathrm{CNT} / \mathrm{CNF}\right)$, and $3 \mathrm{~S} / \mathrm{m}\left(35 \mathrm{mg} / \mathrm{cm}^{3} \mathrm{C}-\mathrm{CNT} / \mathrm{CNF}\right)$. The piezoresistive nature of the nanocomposite foams can be accounted for the rearrangement of the percolated nanotube/nanofiber network 

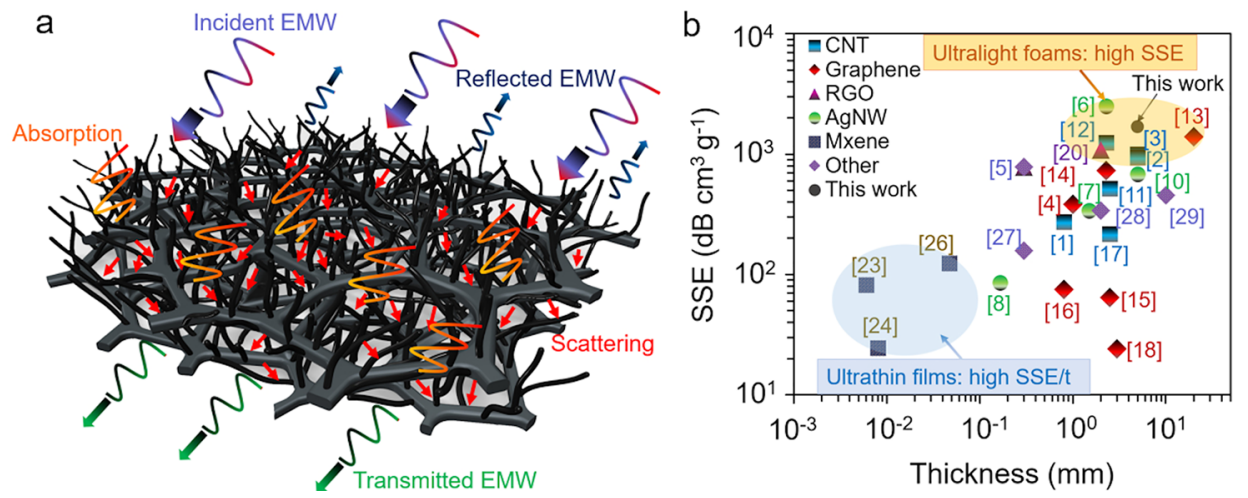

Figure 5. (a) Proposed shielding mechanisms for the composite foams and (b) comparison of SSE as a function of thickness for ultrathin and lightweight composites (at $18 \mathrm{GHz}$ ).

as well as for the local stress-induced change of the electronic band structure in the disordered $\mathrm{sp}^{2}-\mathrm{sp}^{3}$ carbon material of the carbon foam scaffold. ${ }^{36}$ This latter phenomenon has been found particularly relevant for amorphous carbon materials. $^{44,45}$ Notable resistance-strain hysteresis and varying responses for subsequent loading-unloading cycles were present similarly as reported for other carbon foam structures. $^{42,46}$

Furthermore, the $\mathrm{C}-\mathrm{CNT} / \mathrm{CNF}$ nanocomposites show excellent durability and stability for at least 1000 repeated cycles at and applied compressive strain of $20 \%$ (Figure S5, Supporting Information). However, it has to be noted that strains above $\sim 40 \%$ cause a gradual collapse of the structure with significant damage after $\sim 100$ repeated cycles. The measured stresses (at $\varepsilon_{\mathrm{c}}=40 \%$ ) for $\mathrm{C}-\mathrm{CNT} / \mathrm{CNF}$ nanocomposites with densities of 15 and $35 \mathrm{mg} / \mathrm{cm}^{3}$ were approximately 7 and $13 \mathrm{kPa}$ thus the corresponding specific compressive stresses (density normalized compressive stress) are 0.47 and $0.36 \mathrm{MPa} /\left(\mathrm{g} / \mathrm{cm}^{3}\right)$, respectively. Therefore, it can be stated that the resilience and relative strength of the original carbon foam $\left(\sim 0.9 \mathrm{MPa} /\left(\mathrm{g} / \mathrm{cm}^{3}\right)\right)$ is higher than in the nanocomposites.

EMI shielding behavior of $5 \mathrm{~mm}$ thick foams (original and composite with various $\mathrm{CNT} / \mathrm{CNF}$ loading) measured between 18 and $26.5 \mathrm{GHz}$ (K-band frequencies) particularly important for $5 \mathrm{G}$ telecommunication is shown in Figure 4a. The composite foams having different amounts of CNTs/ $\mathrm{CNFs}$ in their structure display superior shielding characteristics (from 20 to $30 \mathrm{~dB}$ depending on the overall mass density) in reference to the parent carbon foam $(1.8 \mathrm{~dB})$. Accordingly, most composite fulfils the technical requirement for the minimum shielding effectiveness $(20 \mathrm{~dB})$. It is worth mentioning here that the corresponding density adjusted specific shielding effectiveness SSE (1700-800 dB cm $\mathrm{g}^{-1}$; Figure $4 \mathrm{~b}$ ) and their thickness normalized values $\mathrm{SSE} / \mathrm{t}$ calculated for the composites are excellent (3400-1600 dB $\left.\mathrm{cm}^{2} \mathrm{~g}^{-1}\right)$.

To understand the reasons of the excellent total shielding effectiveness $\left(\mathrm{SE}_{\mathrm{T}}\right)$, we elaborated in more detail the contributions of its reflection $\left(\mathrm{SE}_{\mathrm{R}}\right)$ and absorption $\left(\mathrm{SE}_{\mathrm{A}}\right)$ loss components (Figure $4 \mathrm{c}$ ). For the composites, $\mathrm{SE}_{\mathrm{R}}$ accounts on approximately $0.5 \mathrm{~dB}$ out of the total $\mathrm{SE}_{\mathrm{T}}$ of 20.5-25.5 dB (measured $18 \mathrm{GHz}$ for the different composites), which corresponds to $\sim 11 \%$ loss of the electromagnetic power by reflection and $\sim 88 \%$ due to the absorbance. Accordingly, only a very small part of the electromagnetic power is reflected back from the surface of the composite, which would be due to the low impedance mismatch at K-band, i.e., close values of dielectric permittivities of air and the highly porous composite (Figure S6, Supporting Information). Such high absorbance with superb shielding performance has been proven difficult to achieve with any other material as of now. Consequently, a major fraction of electromagnetic power penetrates into the foam structure, and the waves experience two types of events during their propagation. One is absorption by the solid phase through polarization and ohmic losses. The other is scattering on the interfaces of air-filled voids (pores) and solid structures (carbon skeleton, CNTs, and CNFs) facilitating an increased optical path of the waves thus making the overall intensity decay highly enhanced. The electromagnetic radiant energy of propagating, scattered, and absorbed waves are eventually converted into heat in the carbon materials. The depicted scattering enhanced shielding mechanism (schematically also displayed in Figure 5a) is expected to be valid also for other heterogeneous multiphase systems including polymer composites with conductive fillers but, however, does not hold for metals (losses are dominated by surface reflection) nor for conductive polymers (lack of good scattering centers in the homogeneous absorber medium). Such good absorption based shielding is of great practical importance since harmful effects of the back-reflected power to the emitting devices or to other components from the shielding materials can be avoided, making the demonstrated hierarchical carbon foams superior compared to conventional materials despite the drawbacks of thickness and frequency dependent shielding efficiency.

Since the electrical conductivity of the composites may be tuned with a great extent by applying mechanical strain on the structures (Figure $3 \mathrm{~d}-\mathrm{f}$ ), we anticipate their EMI shielding behavior is strain dependent too. To verify this, we measure the total shielding effectiveness of the composite foams as a function mechanical strain. As shown in Figure 4d, the value of $\mathrm{SE}_{\mathrm{T}}$ (for the composite of $14 \mathrm{mg} / \mathrm{cm}^{3}$ density) may be increased by compressive strains. The enhancement is significant considering the increase of total loss from 16.4 to $21.6 \mathrm{~dB}$ at $18 \mathrm{GHz}$ (corresponding to $97.7 \%$ and $99.3 \%$ shielding) measured at compressive strains of 12.5 and $40.6 \%$, respectively. It is worth mentioning here that, despite the strain-enhanced total shielding effectiveness, the value of specific effectiveness remains very similar due to the normalization with the increased materials density (Figure 4e). The enhanced SE of the nanocomposites through large piezor- 
esistivity is highly useful to maintain or even improve the shielding functionality of surface mounted materials for deformable devices (flexible electronics, etc.) and multiform and curvilinear surfaces.

To place the demonstrated shielding properties on the map, we compare the most important properties of our composites to other conducting nanocomposites made of CNTs, metal nanowires, and 2-dimensional materials (Figure 5b; Table S3, Supporting Information). The nanocomposites of carbon foam with carbon nanotubes/nanofibers presented in our study compete with the best materials reported in the literature. The achieved values of $\sim 1700 \mathrm{~dB} \mathrm{~cm} \mathrm{~g}^{-1}$ for SSE and $\sim 3380 \mathrm{~dB}$ $\mathrm{cm}^{2} \mathrm{~g}^{-1}$ for SSE/ $\mathrm{t}$ for lightweight $\left(<50 \mathrm{mg} / \mathrm{cm}^{3}\right)$ carbon-based shielding materials are among the highest values. Only costly polyurethane/silver NWs and PEDOT:PSS/graphene nanocomposites showed slightly higher SSE values (2500 and 3130 $\mathrm{dB} \mathrm{cm} \mathrm{cm}^{-1}$, respectively). In contrast, our nanocomposites are not only affordable and have potentially scalable production, but they provide further functionalities, such as waterrepellency and large piezoresistivity that are second to none.

\section{CONCLUSIONS}

Lightweight nanocomposites of carbon foams with carbon nanotubes and nanofibers were synthesized by pyrolysis of melamine foams and subsequent CNT/CNF synthesis using chemical vapor deposition. The highly conductive and lowdensity networks of carbon nanocomposites proved to be highly effective absorber media for electromagnetic waves (SE of $20-30 \mathrm{~dB}$ or SSE of $800-1700 \mathrm{~dB} \mathrm{~cm} \mathrm{~g} \mathrm{~g}^{-1}$ ) in microwave frequencies from 18 to $26.5 \mathrm{GHz}$ important for future $5 \mathrm{G}$ telecommunication networks. Because of the piezoresistive nature of the composites, the shielding effectiveness of the materials was also found to depend on mechanical deformations. Furthermore, the porous carbon nanocomposites showed excellent water-repellency, stability in humid conditions, and mechanical compressibility with excellent cyclic stability and durability, which all add to the very useful functionalities not offered by any other materials.

\section{METHODS}

Carbon Foam Preparation. Melamine foam (BASF, Basotect W) was pyrolyzed in a $4^{\prime \prime}$ quartz tube furnace in nitrogen atmosphere $\left(150 \mathrm{~mL} / \mathrm{min}\right.$ flow). The furnace was first heated with $15{ }^{\circ} \mathrm{C} / \mathrm{min}$ heating rate to $300{ }^{\circ} \mathrm{C}$, after which the rate was lowered to $2{ }^{\circ} \mathrm{C} / \mathrm{min}$ to reach $800{ }^{\circ} \mathrm{C}$ pyrolyzation temperature at which the reactor was kept for $60 \mathrm{~min}$.

CNT/CNF Synthesis. The obtained carbon foam was cut into 30 $\times 10 \times 5 \mathrm{~mm}$ pieces and immersed into containers with $\sim 5.7 \mathrm{~mL}$ of $0.8 \mathrm{~g} / \mathrm{L}$ solution of nickel(II) acetylacetonate (Sigma-Aldrich 283657) in acetone. The containers were then placed in a box furnace heated to $70{ }^{\circ} \mathrm{C}$ and left there for $2 \mathrm{~h}$ to dry. The Ni-precursor loading in the carbon foams were varied between 13 and 24 wt \%. Next, the catalyst precursor impregnated foam pieces were loaded in a 2 " quartz tube furnace for the CNT synthesis. After flushing the reactor with argon, the furnace was first heated to $770{ }^{\circ} \mathrm{C}$ in $500 \mathrm{~mL} / \mathrm{min} \mathrm{Ar}$ flow. After the target temperature was reached, the gas flow was switched off, and $15 \% \mathrm{H}_{2} / \mathrm{Ar}(2000 \mathrm{~mL} / \mathrm{min})$ was introduced into the reactor for $6 \mathrm{~min}$ to reduce the $\mathrm{Ni}(\mathrm{acac})_{2}$ into catalytically active $\mathrm{Ni}$. After the reduction step, $\mathrm{C}_{2} \mathrm{H}_{2}(80 \mathrm{~mL} / \mathrm{min})$ and $\mathrm{Ar}$ through a water bubbler $(70 \mathrm{~mL} / \mathrm{min}$ ) were let into the chamber for $30 \mathrm{~min}$ to facilitate the water-assisted CVD growth of CNTs/CNFs.

Characterization. Field emission scanning electron microscopy (FESEM, Zeiss Ultra Plus, equipped with EDX) and transmission electron microscopy (TEM, JEOL JEM-2200FS EFTEM/STEM 200 $\mathrm{kV}$ ) was used to study the microstructure of the materials. Because of the insulating electrical behavior of the melamine foam $\sim 20 \mathrm{~nm}$ of carbon was sputtered on the polymer samples before imaging. Raman spectroscopy was carried out using a Horiba Jobin-Yvon LabRAM HR800 device with an excitation of $\lambda=488 \mathrm{~nm}$. The elemental composition was assessed by energy dispersive X-ray spectroscopy (EDX) with a detector installed on the FESEM.

Mechanical Stress-Strain and Piezoresistive Measurements. Samples were cut to $\sim 10 \mathrm{~mm} \times 10 \mathrm{~mm} \times 5 \mathrm{~mm}$ sized pieces and placed between two copper plates on a bench consisting of a weighting scale (Precisa LS 620M) connected to a computer and a computer controlled vertical translation stage. The pressing force was calculated from the measured weight upon compression adjusted by the vertical displacement of the upper copper electrode plate. The copper plates were connected to a Keithley 2636A SourceMeter and a constant $5 \mathrm{~V}$ bias was applied while measuring the current.

Electromagnetic Interference Shielding Measurements. Agilent 8517B S-Parameter Test Set with rectangular Keysight WR60 waveguide and a sample holder with dimensions of 10.67 $\mathrm{mm} \times 4.3 \mathrm{~mm} \times 5 \mathrm{~mm}$ were used to measure the scattering parameters $\left(S_{11}\right.$ and $\left.S_{21}\right)$ at K-band frequency range $(18-26.5 \mathrm{GHz})$ in room temperature $\left(23{ }^{\circ} \mathrm{C}\right)$. The scattering parameter (Sparameter) measurements were calibrated with a standard two-port method in forward and reverse directions. The thicknesses of the CCNT/CNF foams were $5 \mathrm{~mm}$. The shielding properties associated with the $S_{11}$ and $S_{21}$-parameters were calculated through eqs $S 2-S 7$ in the Supporting Information.

\section{ASSOCIATED CONTENT}

\section{Supporting Information}

The Supporting Information is available free of charge on the ACS Publications website at DOI: 10.1021/acsami.9b02309.

$\mathrm{X}$-ray tomography and SEM images of the microstructure; low magnification FESEM images of low- and high-density CNT/CNF growth; TEM images of CNT and CNF structures; BET surface areas; thermal diffusivities and thermal conductivities for carbon and $\mathrm{C}-\mathrm{CNT} / \mathrm{CNF}$ nanocomposites; resistance variation in humid conditions for carbon and $\mathrm{C}-\mathrm{CNT} / \mathrm{CNF}$ (30 $\left.\mathrm{mg} / \mathrm{cm}^{3}\right)$; cyclic durability with 1000 repeated cycles at strain of $20 \%$ for C-CNT/CNF (14 and $35 \mathrm{mg} / \mathrm{cm}^{3}$ ); equations for calculating EMI shielding properties; dielectric properties of melamine, carbon, and C$\mathrm{CNT} / \mathrm{CNF}$ ( 28 and $35 \mathrm{mg} / \mathrm{cm}^{3}$ ) at a frequency of $\leq 1$ $\mathrm{MHz}$; comparison of EMI shielding performance of the $\mathrm{C}-\mathrm{CNT} / \mathrm{CNF}$ composite foam to other materials (PDF)

Movie S1: Compression of the $\mathrm{C}-\mathrm{CNT} / \mathrm{CNF}$ foam (AVI)

Movie S2: Hydrophilicity/hydrophobicity of carbon and $\mathrm{C}-\mathrm{CNT} / \mathrm{CNF}$ foams (AVI)

\section{AUTHOR INFORMATION}

\section{Corresponding Author}

*E-mail: olli.pitkanen@oulu.fi.

ORCID

Olli Pitkänen: 0000-0003-2870-3229

Jarkko Tolvanen: 0000-0002-4960-2286

Ákos Kukovecz: 0000-0003-0716-9557

\section{Author Contributions}

Material synthesis was done by O.P. Material characterization was done by O.P., J.T., J.H., and .IZ. The EMI shielding performance measurements were done by J.T. The manuscript was written by O.P. and J.T. with the help of Á.K., J.H., H.J., and K.K. 


\section{Author Contributions}

${ }^{\S}$ O.P. and J.T. contributed equally.

\section{Notes}

The authors declare no competing financial interest.

\section{ACKNOWLEDGMENTS}

The research has been partially funded by projects Grelectronics (1569/31/2017, Business Finland) and 6Genesis Flagship (Grant No. 318927, Academy of Finland). I.S. and Á.K. acknowledge the support of The Ministry of Human Capacities, Hungary, Grant 20391-3/2018/FEKUSTRAT. O.P. acknowledges Riitta and Jorma J. Takanen foundation for their support. The support received from the Micro- and Nanotechnology Center, University of Oulu is also acknowledged.

\section{REFERENCES}

(1) Zeng, Z.; Chen, M.; Jin, H.; Li, W.; Xue, X.; Zhou, L.; Pei, Y.; Zhang, H.; Zhang, Z. Thin and Flexible Multi-walled Carbon Nanotube/Waterborne Polyurethane Composites with High-Performance Electromagnetic Interference Shielding. Carbon 2016, 96, 768777.

(2) Wang, G.; Wang, L.; Mark, L. H.; Shaayegan, V.; Wang, G.; Li, H.; Zhao, G.; Park, C. B. Ultralow-Threshold and Lightweight Biodegradable Porous PLA/MWCNT with Segregated Conductive Networks for High-Performance Thermal Insulation and Electromagnetic Interference Shielding Applications. ACS Appl. Mater. Interfaces 2018, 10, 1195-1203.

(3) Zhang, L.-Q.; Yang, S.-G.; Li, L.; Yang, B.; Huang, H.-D.; Yan, D.-X.; Zhong, G.-J.; Xu, L.; Li, Z.-M. Ultralight Cellulose Porous Composites with Manipulated Porous Structure and Carbon Nanotube Distribution for Promising Electromagnetic Interference Shielding. ACS Appl. Mater. Interfaces 2018, 10, 40156-40167.

(4) Chen, Z.; Xu, C.; Ma, C.; Ren, W.; Cheng, H.-M. Lightweight and Flexible Graphene Foam Composites for High-Performance Electromagnetic Interference Shielding. Adv. Mater. 2013, 25, 12961300.

(5) Ma, X.; Li, Y.; Shen, B.; Zhang, L.; Chen, Z.; Liu, Y.; Zhai, W.; Zheng, W. Carbon Composite Networks with Ultrathin Skin Layers of Graphene Film for Exceptional Electromagnetic Interference Shielding. ACS Appl. Mater. Interfaces 2018, 10, 38255-38263.

(6) Zeng, Z.; Chen, M.; Pei, Y.; Seyed Shahabadi, S. I.; Che, B.; Wang, P.; Lu, X. Ultralight and Flexible Polyurethane/Silver Nanowire Nanocomposites with Unidirectional Pores for Highly Effective Electromagnetic Shielding. ACS Appl. Mater. Interfaces 2017, 9, 32211-32219.

(7) Yuan, Y.; Sun, X.; Yang, M.; Xu, F.; Lin, Z.; Zhao, X.; Ding, Y.; Li, J.; Yin, W.; Peng, Q.; He, X.; Li, Y. Stiff, Thermally Stable and Highly Anisotropic Wood-Derived Carbon Composite Monoliths for Electromagnetic Interference Shielding. ACS Appl. Mater. Interfaces 2017, 9, 21371-21381.

(8) Lee, T.-W.; Lee, S.-E.; Jeong, Y. G. Highly Effective Electromagnetic Interference Shielding Materials based on Silver Nanowire/Cellulose Papers. ACS Appl. Mater. Interfaces 2016, 8, 13123-13132.

(9) Jia, L.-C.; Yan, D.-X.; Liu, X.; Ma, R.; Wu, H.-Y.; Li, Z.-M. Highly Efficient and Reliable Transparent Electromagnetic Interference Shielding Film. ACS Appl. Mater. Interfaces 2018, 10, 1194111949.

(10) Ma, J.; Zhan, M.; Wang, K. Ultralightweight Silver Nanowires Hybrid Polyimide Composite Foams for High-Performance Electromagnetic Interference Shielding. ACS Appl. Mater. Interfaces 2015, 7, $563-576$.

(11) Huang, H.-D.; Liu, C.-Y.; Zhou, D.; Jiang, X.; Zhong, G.-J.; Yan, D.-X.; Li, Z.-M. Cellulose Composite Aerogel for Highly Efficient Electromagnetic Interference Shielding. J. Mater. Chem. A 2015, 3, 4983-4991.
(12) Zeng, Z.; Jin, H.; Chen, M.; Li, W.; Zhou, L.; Zhang, Z. Lightweight and Anisotropic Porous MWCNT/WPU Composites for Ultrahigh Performance Electromagnetic Interference Shielding. Adv. Funct. Mater. 2016, 26, 303-310.

(13) Shen, B.; Li, Y.; Zhai, W.; Zheng, W. Compressible GrapheneCoated Polymer Foams with Ultralow Density for Adjustable Electromagnetic Interference (EMI) Shielding. ACS Appl. Mater. Interfaces 2016, 8, 8050-8057.

(14) Ling, J.; Zhai, W.; Feng, W.; Shen, B.; Zhang, J.; Zheng, W. Facile Preparation of Lightweight Microcellular Polyetherimide/ Graphene Composite Foams for Electromagnetic Interference Shielding. ACS Appl. Mater. Interfaces 2013, 5, 2677-2684.

(15) Yan, D.-X.; Ren, P.-G.; Pang, H.; Fu, Q.; Yang, M.-B.; Li, Z.-M. Efficient Electromagnetic Interference Shielding of Lightweight Graphene/Polystyrene Composite. J. Mater. Chem. 2012, 22, 18772-18774.

(16) Li, Y.; Pei, X.; Shen, B.; Zhai, W.; Zhang, L.; Zheng, W. Polyimide/Graphene Composite Foam Sheets with Ultrahigh Thermostability for Electromagnetic Interference Shielding. RSC Adv. 2015, 5, 24342-24351.

(17) Li, X.-H.; Li, X.; Liao, K.-N.; Min, P.; Liu, T.; Dasari, A.; Yu, Z.Z. Thermally Annealed Anisotropic Graphene Aerogels and Their Electrically Conductive Epoxy Composites with Excellent Electromagnetic Interference Shielding Efficiencies. ACS Appl. Mater. Interfaces 2016, 8, 33230-33239.

(18) Hamidinejad, M.; Zhao, B.; Zandieh, A.; Moghimian, N.; Filleter, T.; Park, C. B. Enhanced Electrical and Electromagnetic Interference Shielding Properties of Polymer-Graphene Nanoplatelet Composites Fabricated via Supercritical-Fluid Treatment and Physical Foaming. ACS Appl. Mater. Interfaces 2018, 10, 30752-30761.

(19) Wu, Y.; Wang, Z.; Liu, X.; Shen, X.; Zheng, Q.; Xue, Q.; Kim, J.-K. Ultralight Graphene Foam/Conductive Polymer Composites for Exceptional Electromagnetic Interference Shielding. ACS Appl. Mater. Interfaces 2017, 9, 9059-9069.

(20) Zeng, Z.; Zhang, Y.; Ma, X. Y. D.; Shahabadi, S. I. S.; Che, B.; Wang, P.; Lu, X. Biomass-Based Honeycomb-like Architectures for Preparation of Robust Carbon Foams with High Electromagnetic Interference Shielding Performance. Carbon 2018, 140, 227-236.

(21) Xu, F.; Chen, R.; Lin, Z.; Qin, Y.; Yuan, Y.; Li, Y.; Zhao, X.; Yang, M.; Sun, X.; Wang, S.; Peng, Q.; Li, Y.; He, X. Superflexible Interconnected Graphene Network Nanocomposites for HighPerformance Electromagnetic Interference Shielding. ACS Omega. 2018, 3, 3599-3607.

(22) Lai, D.; Chen, X.; Liu, X.; Wang, Y. Flexible Poly(vinyl alcohol)/Reduced Graphene Oxide Coated Carbon Composites for Electromagnetic Interference Shielding. ACS Appl. Nano Mater. 2018, $1,5854-5864$.

(23) Liu, J.; Zhang, H.-B.; Sun, R.; Liu, Y.; Liu, Z.; Zhou, A.; Yu, Z.Z. Hydrophobic, Flexible, and Lightweight MXene Foams for HighPerformance Electromagnetic-Interference Shielding. Adv. Mater. 2017, 29, 1702367.

(24) Shahzad, F.; Alhabeb, M.; Hatter, C. B.; Anasori, B.; Man Hong, S.; Koo, C. M.; Gogotsi, Y. Electromagnetic Interference Shielding with 2D Transition Metal Carbides (MXenes). Science 2016, 353, 1137.

(25) Zhao, S.; Zhang, H.-B.; Luo, J.-Q.; Wang, Q.-W.; Xu, B.; Hong, S.; Yu, Z.-Z. Highly Electrically Conductive Three-Dimensional $\mathrm{Ti}_{3} \mathrm{C}_{2} \mathrm{~T}_{\mathrm{x}}$ MXene/Reduced Graphene Oxide Hybrid Aerogels with Excellent Electromagnetic Interference Shielding Performances. ACS Nano 2018, 12, 11193-11202.

(26) Cao, W.-T.; Chen, F.-F.; Zhu, Y.-J.; Zhang, Y.-G.; Jiang, Y.-Y.; Ma, M.-G.; Chen, F. Binary Strengthening and Toughening of MXene/Cellulose Nanofiber Composite Paper with Nacre-Inspired Structure and Superior Electromagnetic Interference Shielding Properties. ACS Nano 2018, 12, 4583-4593.

(27) Chen, Z.; Yi, D.; Shen, B.; Zhang, L.; Ma, X.; Pang, Y.; Liu, L.; Wei, X.; Zheng, W. Semi-Transparent Biomass-Derived Macroscopic Carbon Grids for Efficient and Tunable Electromagnetic Shielding. Carbon 2018, 139, 271-278. 
(28) Zhang, L.; Liu, M.; Roy, S.; Chu, E. K.; See, K. Y.; Hu, X. Phthalonitrile-Based Carbon Foam with High Specific Mechanical Strength and Superior Electromagnetic Interference Shielding Performance. ACS Appl. Mater. Interfaces 2016, 8, 7422-7430.

(29) Li, Y.-Q.; Samad, Y. A.; Polychronopoulou, K.; Liao, K. Lightweight and Highly Conductive Aerogel-like Carbon from Sugarcane with Superior Mechanical and EMI Shielding Properties. ACS Sustainable Chem. Eng. 2015, 3, 1419-1427.

(30) Pham, T. N.; Samikannu, A.; Kukkola, J.; Rautio, A.-R.; Pitkänen, O.; Dombovari, A.; Lorite, G. S.; Sipola, T.; Toth, G.; Mohl, M.; Mikkola, J.-P.; Kordas, K. Industrially Benign Super-Compressible Piezoresistive Carbon Foams with Predefined Wetting Properties: from Environmental to Electrical Applications. Sci. Rep. 2015, 4, 6933.

(31) Chen, S.; He, G.; Hu, H.; Jin, S.; Zhou, Y.; He, Y.; He, S.; Zhao, F.; Hou, H. Elastic Carbon Foam via Direct Carbonization of Polymer Foam for Flexible Electrodes and Organic Chemical Absorption. Energy Environ. Sci. 2013, 6, 2435-2439.

(32) Lee, J.-S.; Park, G. S.; Kim, S. T.; Liu, M.; Cho, J. A Highly Efficient Electrocatalyst for the Oxygen Reduction Reaction: NDoped Ketjenblack Incorporated into $\mathrm{Fe} / \mathrm{Fe}_{3} \mathrm{C}$-Functionalized Melamine Foam. Angew. Chem., Int. Ed. 2013, 52, 1026-1030.

(33) Pham, T. N.; Sharifi, T.; Sandström, R.; Siljebo, W.; Shchukarev, A.; Kordas, K.; Wågberg, T.; Mikkola, J.-P. Robust Hierarchical 3D Carbon Foam Electrode for Efficient Water Electrolysis. Sci. Rep. 2017, 7, 6112.

(34) Sousa, J. P. S.; Silva, A. M. T.; Pereira, M. F. R.; Figueiredo, J. L. Wet Air Oxidation of Aniline Using Carbon Foams and Fibers Enriched with Nitrogen. Sep. Sci. Technol. 2010, 45, 1546-1554.

(35) Liu, W.; Liu, N.; Yue, Y.; Rao, J.; Luo, C.; Zhang, H.; Yang, C.; Su, J.; Liu, Z.; Gao, Y. A Flexible and Highly Sensitive Pressure Sensor Based on Elastic Carbon Foam. J. Mater. Chem. C 2018, 6, 14511458.

(36) Kordas, K.; Pitkänen, O. Piezoresistive Carbon Foams in Sensing Applications. Front. Mater. 2019, 6, 93.

(37) Xiao, K.; Ding, L.-X.; Liu, G.; Chen, H.; Wang, S.; Wang, H. Freestanding, Hydrophilic Nitrogen-Doped Carbon Foams for Highly Compressible All Solid-State Supercapacitors. Adv. Mater. 2016, 28, 5997-6002.

(38) Wang, L.; Fu, Y.; Chen, Y.; Li, Y.; Zhou, R.; Chen, S.; Song, Y. Ultralight flower ball-like $\mathrm{Co}_{3} \mathrm{O}_{4} /$ Melamine-Derived Carbon Foam as Anode Materials for Lithium-Ion Batteries. J. Alloys Compd. 2017, 724, 1117-1123.

(39) Xiang, M.; Yang, L.; Zheng, Y.; Huang, J.; Jing, P.; Wu, H.; Zhang, Y.; Liu, H. A Freestanding and Flexible Nitrogen-Doped Carbon Foam/Sulfur Cathode Composited with Reduced Graphene Oxide for High Sulfur Loading Lithium-Sulfur Batteries. J. Mater. Chem. A 2017, 5, 18020-18028.

(40) Zhou, Z.; Zhang, H.; Zhou, Y.; Qiao, H.; Gurung, A.; Naderi, R.; Elbohy, H.; Smirnova, A. L.; Lu, H.; Chen, S.; Qiao, Q. Binder Free Hierarchical Mesoporous Carbon Foam for High Performance Lithium Ion Battery. Sci. Rep. 2017, 7, 1440.

(41) Sun, Y.; Luo, S.; Sun, H.; Zeng, W.; Ling, C.; Chen, D.; Chan, V.; Liao, K. Engineering Closed-cell Structure in Lightweight and Flexible Carbon Foam Composite for High-efficient Electromagnetic Interference Shielding. Carbon 2018, 136, 299-308.

(42) Tolvanen, J.; Hannu, J.; Jantunen, H. Hybrid Foam Pressure Sensor Utilizing Piezoresistive and Capacitive Sensing Mechanisms. IEEE Sens. J. 2017, 17, 4735-4746.

(43) Lee, J.; Tejedor, E.; Ranta-Aho, K.; Wang, H.; Lee, K.; Semaan, E.; Mohyeldin, E.; Song, J.; Bergljung, C.; Jung, S. Spectrum for 5G: Global Status, Challenges, and Enabling Technologies. IEEE Comm. Mag. 2018, 56, 12-18.

(44) Grimaldi, C.; Ryser, P.; Strässler, S. Gauge Factor of Thick-film Resistors: Outcomes of the Variable-Range-Hopping Model. J. Appl. Phys. 2000, 88 (7), 4164-4169.

(45) Peiner, E.; Tibrewala, A.; Bandorf, R.; Biehl, S.; Lüthje, H.; Doering, L. Micro Force Sensor with Piezoresistive Amorphous Carbon Strain Gauge. Sens. Actuators, A 2006, 130-131, 75-82.
(46) Tolvanen, J.; Hannu, J.; Nelo, M.; Juuti, J.; Jantunen, H. Dielectric Properties of Novel Polyurethane-PZT-Graphite Foam Composites. Smart Mater. Struct. 2016, 25, 095039. 